\title{
Is captive breeding a priority for manatee conservation in Mexico?
}

\author{
Alejandro Ortega - Argueta and Delma Nataly Castelblanco-Martínez
}

\begin{abstract}
The Endangered Antillean manatee Trichechus manatus manatus is one of the most threatened aquatic mammal species in Mexico and the wider Caribbean region. The decline of this subspecies is mainly a result of historical exploitation and the impact of current coastal development. The conservation strategies adopted for the Antillean manatee include habitat protection, reduction of the most severe threats, and the rescue of stranded, orphaned or injured individuals and their management in captivity. This latter strategy has produced positive outcomes in some countries but has been the subject of controversy in others, including Mexico. We analyse the benefits and challenges associated with the management of captive manatees in Mexico, and the consequences of a lack of government policy and strategy for the post-rehabilitation release of individuals. We describe the evolution of this controversy from 1997-2017 in Mexico, analyse the consequences and implications for the conservation of the species, and propose an integrated management strategy that could address the issues raised. Although this strategy has been developed in the context of Mexico, it is applicable to management of this species across the Caribbean region.
\end{abstract}

Keywords Antillean manatee, captive breeding, captive management, decision-making, Mexico, post-rehabilitation release, threatened species recovery, Trichechus manatus

\section{Introduction}

The Antillean manatee Trichechus manatus manatus is 1 one of the most threatened aquatic mammal species across its range in eastern North, Central and South America. In Mexico, it occurs along the coasts of the Gulf of Mexico and the eastern Yucatan Peninsula (ColmeneroRolón \& Hoz, 1986; Morales-Vela \& Olivera-Gómez, 1997) as two genetically distinct populations (Nourisson et al., 2011). An estimated 1,000-1,500 manatees inhabit Mexican waters (Castelblanco-Martínez et al., 2012).

\footnotetext{
Alejandro Ortega-Argueta (Corresponding author) El Colegio de la Frontera Sur, Unidad Villahermosa, Carretera a Reforma km. 15.5, Rancheria Guineo 2a. Sección, Villahermosa, Tabasco 86280, Mexico. E-mail aortega@ecosur.mx

Delma Nataly Castelblanco-Martínez Consejo Nacional de Ciencia y Tecnología, Universidad de Quintana Roo, Quintana Roo, Mexico

Received 15 June 2017. Revision requested 27 July 2017.

Accepted 3 November 2017. First published online 2 May 2018.
}

Threats to manatees include poaching, entanglement in fishing nets and habitat loss caused by intensive coastal development (Morales-Vela \& Olivera-Gómez, 1997; OrtegaOrtiz et al., 2004). To address these threats, priority conservation strategies are being directed towards effective management for recovery (Quintana-Rizzo \& Reynolds, 2010; SEMARNAT/CONANP, 2010). One of the management strategies is the rescue of injured or stranded manatees and their transfer to rehabilitation facilities. Although captive breeding of threatened species is a widespread conservation strategy (IUCN, 1998), it is not always feasible or justifiable as a management priority (Hunter et al., 2013). Decision-making in conservation needs to take into account complex social considerations and is subject to human emotivity (Ainsworth et al., 2016), which can lead to erroneous or late decisions with unintended or unforeseen management outcomes (Wilson et al., 2009; Brook et al., 2014). In the management of threatened species, attention can be diverted to unnecessary or lower priority actions, with costly consequences in terms of funding and achievement of recovery goals (Pérez et al., 2012). Here we document a controversy surrounding the captive management and breeding of manatees in Mexico, examining whether captive breeding is a priority for manatee conservation. We describe the evolution of this controversy over 2 decades (1997-2017) and analyse the consequences of the decisions made and the implications for manatee conservation, and, to address these issues, propose an integrated management strategy that involves aspects of both in situ and ex situ conservation. Although this analysis was carried out in the context of Mexico, it is relevant and applicable to the management of this species across the wider Caribbean region.

\section{Conservation benefits of manatee management in captivity}

Manatees can be injured or orphaned as a result of anthropogenic or natural events and become dependent on rescue and rehabilitation in appropriate facilities. Partnerships of government authorities with state and private zoos play an important role by providing the necessary veterinary care, husbandry and research opportunities. Such partnerships have been established successfully in the USA (including Puerto Rico), Brazil and Venezuela, where manatees have been held in captivity (Adimey et al., 2012; Normande 
et al., 2015; Boede \& Mujica-Jorquera, 2016). Manatees are difficult to study in the wild and therefore the knowledge and expertise gained through management of captive individuals is of great value. Manatees in captivity have also generated greater public awareness and support for their conservation (Adimey et al., 2012).

Manatee rescue and rehabilitation has a long history, particularly in the USA (Adimey et al., 2012, 2016) and Brazil (Normande et al., 2015). Rehabilitation programmes involve the provision of veterinary care, rearing of orphaned animals and the subsequent release of viable individuals into suitable wild habitat (Miller, 200o). The release of individuals into an existing population is referred to as reinforcement or restocking (IUCN, 1998). Several protocols for manatee rehabilitation have been developed by major conservation programmes in the Caribbean region (Lima et al., 2007; Adimey et al., 2012).

Manatees can adapt to captivity within a matter of weeks (Bonde et al., 2003) but contact with humans can alter their behaviour and reaction to natural hazards; the animals become docile and attached to humans. Manatees that are maintained for long periods or were born in captivity also lack the instinct to avoid risks such as boats and gillnets, two major causes of manatee mortality. Docile manatees are unlikely to survive in the wild because they lack the ability to exploit habitats where they can find food and shelter, and face the difficulty of integrating into existing populations (Bonde et al., 2003). Experience in Florida suggests that manatees held in captivity for less than 2 years face fewer challenges after release than those held for longer periods (Bonde et al., 2003; Adimey et al., 2016).

\section{Captive breeding as a recovery strategy for threatened species}

Captive breeding is a widely used conservation strategy for species with diminished populations in the wild. Captive animals represent a demographic and genetic reservoir that can be used for restocking (IUCN, 1998), but captive breeding is not always feasible. Experience from the USA (including Puerto Rico) and Brazil has shown that breeding manatees in captivity (Corkeron, 2002) presents biological and financial challenges (Adimey et al., 2012). Manatees have a relatively low reproduction rate: they reach sexual maturity after 5 years, have a gestation period of 11-13 months, give birth to a single calf and the average interval between births is 2.5 years (Marmontel et al., 1992). The high cost of maintaining manatees in captivity, up to USD 16,700 annually per individual (R. Sánchez-Ockruky, Dolphin Discovery, Mexico, pers. comm.), makes it difficult to secure the necessary financial resources, especially in developing countries such as Mexico. Long-term recovery based on captive breeding programmes is therefore unviable (Bossart, 1999); it can only be an interim solution that can be expected to remain relatively expensive (Snyder et al., 1997). In the USA (including Puerto Rico), Belize and Brazil manatees have been kept in captivity only long enough to rehabilitate them, and have been released as soon as possible, thus minimizing costs and avoiding habituation to people (Lima et al., 2007; Adimey et al., 2012).

\section{7-2007: manatee management controversy}

Capture of manatees is prohibited in Mexico, with the exception of capture for rescue or research purposes by accredited institutions. In 1997 a programme of the Ministry of the Environment and Natural Resources began, with a focus on the recovery of threatened species. This included the creation of technical advisory committees: autonomous multi-stakeholder bodies that aimed to advise management decisions, and comprised government officials, scientists, representatives of the private sector (parks and zoos), non-governmental organizations and community groups. During this first decade, the manatee advisory committee worked as a recovery team, coordinating and implementing management actions such as manatee rescues and research. An intensive national campaign was launched to raise awareness and encourage community involvement in manatee conservation in the entire distribution range, with members of the manatee recovery team conducting informal educational talks and distributing promotional materials such as t-shirts and pamphlets. This resulted in an increase in the number of reported manatee incidents (e.g. entanglement in fishing nets). Because there is no federal governmental facility for manatee rehabilitation, the rescued manatees were immediately transferred to state and private zoos with suitable facilities, trained personnel and accredited management programmes. With more manatees being rescued every year and ongoing captive breeding, the number of individuals in captivity increased from $<10$ animals in four facilities to 40 in 10 facilities (Table 1; Fig. 1). Of the current captive manatee population in Mexico, at least 37.5\% $(\mathrm{n}=15)$ are captive-born.

The collaboration of parks and zoos, as rehabilitation centres, with government authorities was of great significance, as they participated in all rescues on a voluntary basis and covered most of the maintenance and rehabilitation costs of the manatees in captivity. It was seen as beneficial for all parties because government authorities gained financial and technical support for manatee rehabilitation and the parks and zoos obtained manatees for exhibition.

However, the management programmes of the accredited facilities did not include agreed objectives regarding the post-rehabilitation release of manatees, and there were also gaps in the relevant legislation, such as the protocols for marine mammal rehabilitation and release (NOM-135SEMARNAT-2004). Authorities typically had to respond 
TABLE 1 Captivity facilities and captive manatees in Mexico (see Fig. 1 for locations), detailing manatee ID, gender, age class, date of birth, date of admission and origin of individuals as of December 2017, based on information obtained in our own research and including information from SEMARNAT/CONANP (2010). During our research of official documents (obtained through the National Institute for Transparency, Access to Information and Personal Data Protection), we observed inconsistencies and variations in the documentation of the number of facilities and captive manatees. We validated official information through consultation with personnel from the relevant facilities but some numbers may not be up-to-date because of subsequent manatee rescues, translocations between parks, births and mortality.

\begin{tabular}{|c|c|c|c|c|c|c|}
\hline Facility (by state) & Manatee ID & Gender & Age class ${ }^{*}$ & Date of birth & Date of admission & Origin \\
\hline \multicolumn{7}{|l|}{ Veracruz } \\
\hline \multirow[t]{5}{*}{ (1) Veracruz Aquarium } & Silvia & Female & Adult & Unknown & 1998 & Wild \\
\hline & Dominga & Female & Adult & Unknown & 2002 & Wild \\
\hline & Costeña & Female & Adult & Unknown & 2002 & Wild \\
\hline & Camilo & Male & Adult & $13 / 11 / 2012$ & $13 / 11 / 2012$ & Captive-born \\
\hline & Máximo & Male & Young & $19 / 11 / 2013$ & $19 / 11 / 2013$ & Captive-born \\
\hline
\end{tabular}

Tabasco

(2) Yumka

(3) University of Tabasco

Chiapas

(4) Aluxes Ecopark

\section{Quintana Roo}

(5) Xel-ha

(6) Dolphin Discovery Puerto Aventuras

(7) Dolphin Discovery Puerto Aventuras Dreams

(8) Experiencias Xcaret

(9) Dolphin Discovery Isla Cozumel

(10) Dolphin Discovery Isla Mujeres

\begin{tabular}{|c|c|c|c|c|c|}
\hline Jobo & Unknown & Unknown & Unknown & Unknown & Unknown \\
\hline Pepe & Male & Unknown & Unknown & Unknown & Wild \\
\hline Maxi & Female & Unknown & Unknown & Unknown & Wild \\
\hline Chaca & Female & Unknown & Unknown & Unknown & Wild \\
\hline Chilbek & Female & Unknown & Unknown & Unknown & Wild \\
\hline Itzia & Female & Calf & $08 / 2016$ & $14 / 08 / 2016$ & Wild \\
\hline Marina & Unknown & Adult & $26 / 12 / 2004$ & $03 / 07 / 2005$ & Captive-born \\
\hline Sireni & Female & Adult & $18 / 06 / 2006$ & 03/07/2005 & Captive-born \\
\hline Catazajá & Female & Adult & Unknown & $15 / 05 / 2013$ & Wild \\
\hline Ha’al & Male & Young & Unknown & $01 / 11 / 2013$ & Wild \\
\hline Tunich & Unknown & Young & $28 / 02 / 2012$ & $28 / 02 / 2012$ & Captive-born \\
\hline Nikte & Female & Young & $20 / 06 / 2013$ & $20 / 06 / 2013$ & Captive-born \\
\hline Pablo & Male & Adult & Unknown & 1998 & Wild \\
\hline Romeo & Male & Adult & Unknown & $05 / 01 / 2001$ & Wild \\
\hline Julieta & Female & Adult & Unknown & $05 / 01 / 2001$ & Wild \\
\hline Dorothy & Female & Adult & Unknown & $09 / 05 / 2003$ & Wild \\
\hline Quijote & Male & Adult & $19 / 03 / 2008$ & $19 / 03 / 2008$ & Captive-born \\
\hline Conchis & Female & Young & $15 / 08 / 2014$ & $15 / 08 / 2014$ & Captive-born \\
\hline Clau & Female & Young & $17 / 12 / 2014$ & $17 / 12 / 2014$ & Captive-born \\
\hline Nohoch_2 & Male & Calf & $20 / 03 / 2016$ & $20 / 03 / 2016$ & Captive-born \\
\hline Bombon & Female & Calf & $10 / 04 / 2016$ & $10 / 04 / 2016$ & Captive-born \\
\hline Roberto & Male & Adult & Unknown & $29 / 05 / 2009$ & Wild \\
\hline Lorenzo & Male & Young & $09 / 11 / 2012$ & $09 / 11 / 2012$ & Captive-born \\
\hline Nohoch_1 & Male & Adult & Unknown & 01/01/1999 & Wild \\
\hline Pompom & Female & Adult & Unknown & 01/01/1999 & Wild \\
\hline Mach & Male & Adult & Unknown & $28 / 05 / 2005$ & Wild \\
\hline Buul & Male & Adult & $21 / 01 / 2009$ & $21 / 01 / 2009$ & Captive-born \\
\hline Baxal & Female & Adult & $01 / 01 / 2013$ & $01 / 02 / 2013$ & Wild \\
\hline Dayami & Female & Young & Unknown & $22 / 07 / 2013$ & Wild \\
\hline Yoltzin & Male & Adult & $22 / 08 / 2005$ & $22 / 08 / 2005$ & Wild \\
\hline Angel & Male & Adult & Unknown & 09/07/2007 & Wild \\
\hline Edgar & Male & Adult & $09 / 09 / 2010$ & $09 / 09 / 2010$ & Captive-born \\
\hline Sabina & Female & Adult & Unknown & $07 / 09 / 2007$ & Wild \\
\hline César & Male & Adult & Unknown & $07 / 07 / 2007$ & Wild \\
\hline Fabian & Male & Adult & 2010 & 2010 & Captive-born \\
\hline
\end{tabular}

*Age classes were defined according to calf dependency and age of sexual maturity, estimated by Hartman (1979) for Trichechus manatus, as follows: calf $(<2$ years old), young $(2-5$ years old) and adult $(>5$ years old $)$. 


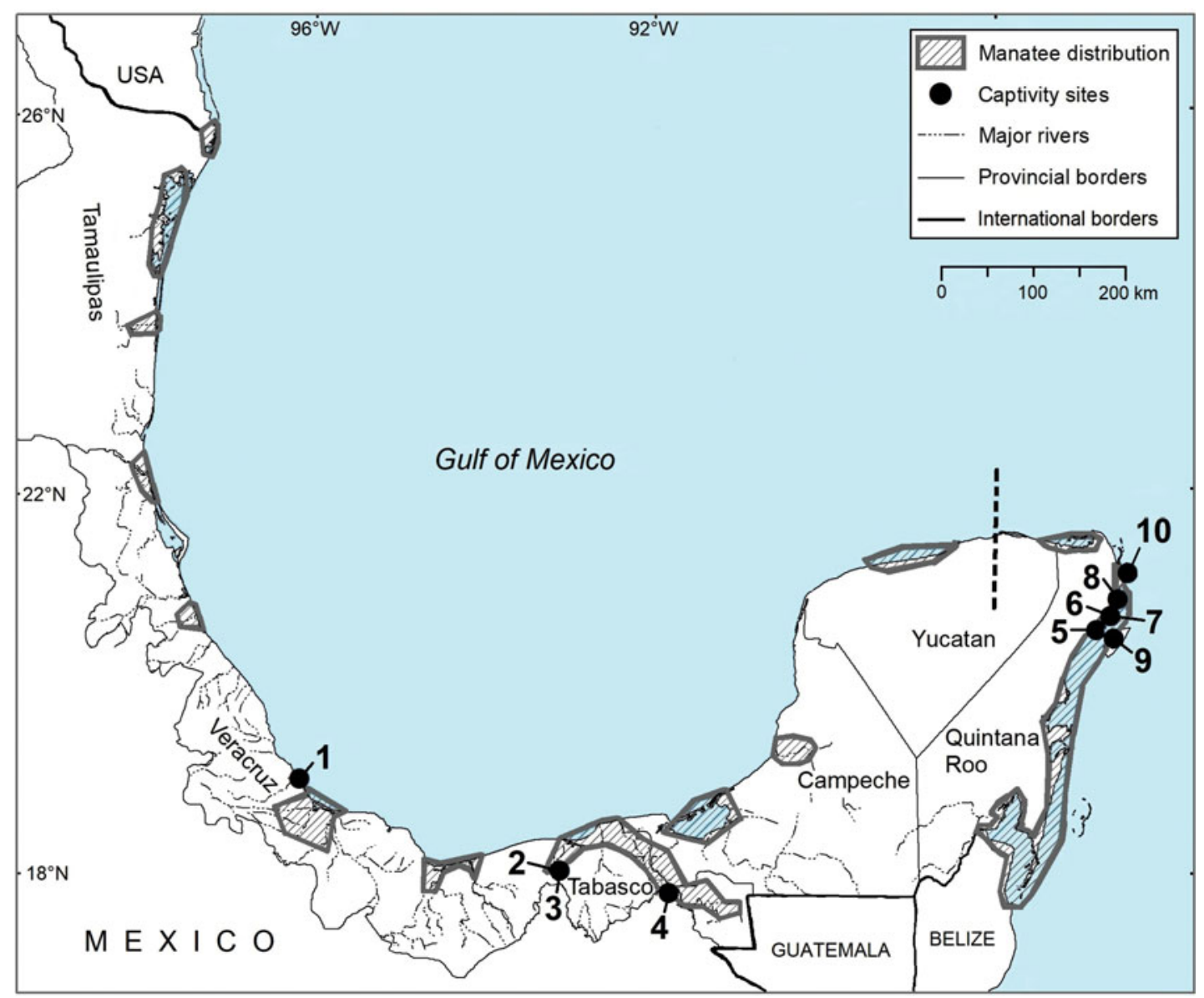

FIG. 1 Manatee distribution areas and captivity sites (Table 1) in Mexico, as of December 2017 based on information obtained in our own research and including information from SEMARNAT/CONANP (2010). Shaded areas indicate where direct (sightings of live manatees, bones or carcasses) and indirect (manatee presence reported in interviews; evidence of feeding areas) records of wild manatees have been obtained during 1997-2017. Facilities with manatees in captivity: (1) Veracruz Aquarium; (2) Yumka; (3) University of Tabasco; (4) Aluxes Ecopark, Palenque; (5) Xel-ha; (6) Dolphin Discovery Puerto Aventuras; (7) Dolphin Discovery Puerto Aventuras Dreams; (8) Experiencias Xcaret; (9) Dolphin Discovery Isla Cozumel and (10) Dolphin Discovery Isla Mujeres. The dashed line on the Yucatan Peninsula indicates the geographical border between the two genetic clusters: the Gulf of Mexico and the Caribbean Sea (Nourisson et al., 2011).

to reported incidents urgently and authorized all rescues and transportation to care facilities. The increase in the number of captive manatees and the lack of official protocols for rehabilitation and release prompted discussions within the advisory committee on how government authorities should proceed to manage the rescued animals once they became independent, healthy and ready for release. Captive breeding is not a necessary conservation strategy for the species according to international management plans (Quintana-Rizzo \& Reynolds, 2010), but some of the advisory committee justified the breeding of manatees as an opportunity for gaining expertise and conducting research and education activities. Others on the committee argued for the preparation of a management strategy with clear criteria for assessing rehabilitation and release attempts. At this point, no decision was made regarding planning for either the immediate or future management needs of the species. In this situation of undefined government management strategy, lack of leadership, and polarized views on rehabilitation objectives, all captive manatees were treated according to the care practices of each individual facility and were mostly domesticated, with no consideration of the international protocols for reintroduction to the wild and restocking of existing populations.

\section{7-2017: weakening manatee conservation}

In 2007 all advisory committees were dissolved following administrative changes. The authorizations of manatee rescues and transfers by the Ministry of the Environment and Natural Resources no longer depended on discussions with the advisory committee. Several changes occurred that had negative consequences for the conservation of manatees. 
Firstly, the lack of consideration given to the genetic structure of the population in management decisions is of concern. Despite the fact that two manatee populations have been identified (Fig. 1; Nourisson et al., 2011), several manatees from the Gulf of Mexico were transferred to facilities on the Yucatan Peninsula, with no intention of release. A second concern is the lack of effort dedicated to the preparation of manatees for post-rehabilitation release. To date, only three animals have been released, with mixed results. In 1999, a manatee was rescued in Belize, transported to and rehabilitated in a private park in Mexico and released back into the wild in Belize after two years, where it apparently survived (Sánchez Okrucky, 2009). The second manatee was rescued in 2003 in Chetumal Bay, and kept in semicaptivity for 7 years. This individual became attached to humans and attempts to release it failed several times (Mercadillo-Elguero et al., 2014). However, in 2015 this manatee began to explore larger areas, travelling distances of up to $145 \mathrm{~km}$ along the coastline (Morales-Vela 2017). The third manatee was a rescued orphan kept in the Alvarado Lagoon, reared by locals for 3 years and released with no monitoring (B. Cortina, pers. comm.). To our knowledge, no further releases are currently planned. A third cause for concern is the ongoing growth of the captive population of manatees, with little consideration given to the impact of inbreeding in some facilities. The number of manatees has also reached the maximum capacity of some facilities, which undermines their potential to receive and care for manatees in need of rescue.

Another major concern is the lack of government financial resources for manatee rehabilitation. Private parks, zoos and conservation groups are of paramount importance in sustaining rehabilitation activities, but they are using their limited resources to keep manatees in captivity for long periods. Investment in activities such as habitat protection and restoration could be of greater benefit for the long-term conservation of the species. The parks and zoos have a genuine interest in caring for the animals, but by pursuing their own objectives they have lost sight of the full extent of manatee recovery issues and have failed to adopt optimal release strategies that would be more beneficial to the population. These strategies are presented in the Manatee Recovery Programme of Mexico (SEMARNAT/CONANP, 2010).

In 2011 technical protocols to guide manatee rehabilitation and release were developed by members of the former advisory committee (Morales-Vela et al., 2012). Nevertheless, most manatees have been maintained in captivity for a decade or more, benefitting the parks' objectives. Although parks, zoos, community groups and academic institutions can potentially provide capacity and expertise for the development and implementation of a restocking management strategy, there is no longer the debate among former advisory committee members and government authorities that could make this a reality.
The benefits of keeping manatees in captivity were explicitly discussed within the advisory committee. These include the rescue and survival of the affected animals, the experience and expertise acquired by park and zoo personnel, the establishment of adequate equipment and holding facilities, the knowledge gained from research and the creation of educational and awareness programmes that have reached a wider public audience. However, the costs and potential negative outcomes of these management choices were not explicitly debated in the decision-making groups of the advisory committee and authorities.

The costs and consequences (including ecological and strategic) of not releasing manatees back into the wild are difficult to gauge. In the context of Mexico, with a population of 1,000-1,500 manatees, removal of 40 animals may not be significant. However, in the context of other countries in the region, such as Honduras and Trinidad and Tobago with populations of $<100$ individuals (QuintanaRizzo \& Reynolds, 2010), the removal of 40 manatees from the wild population would be significant for persistence of a population. Despite this uncertainty, government authorities have failed to take adequate measures to prevent more manatees from being domesticated in captivity.

Management decisions should be made while there is an opportunity to act (Martin et al., 2012). In the present case, an unforeseen cost was the loss of momentum. As a partnership group, the advisory committee played an important role, not only through provision of technical advice and planning support, but also by undertaking multiple conservation initiatives and implementing the manatee recovery programme. Most of the management strategies and actions required the collaboration and coordination of all committee stakeholders (SEMARNAT/CONANP, 2010). The establishment of technical committees and partnerships with relevant stakeholders can support limited government capacity to address the complexity of recovery plans, as demonstrated in Belize (Auil, 1998) and the USA (Abellera et al., 2007). For the manatee in Mexico this multidisciplinary capacity was lost when the advisory committee was dissolved. The development of a post-rehabilitation release strategy was not only postponed, but abandoned. As a consequence, the Ministry of the Environment and Natural Resources and the manatee management programme lost accountability and their ability to implement recovery. With no explicit debate of the actions (or inaction) and their consequences, decision-makers could not estimate how a given choice might contribute to meeting important management objectives.

\section{A way forward for manatee management in Mexico}

The national capacity to develop an integrated management strategy is potentially adequate. Addressing the issues 
identified here requires political will, rather than technical and monetary capacities. The Ministry of the Environment and Natural Resources could work strategically, adopting a precautionary approach, on four aspects of management:

(1) Although parks and zoos have been successful in breeding manatees in captivity in Mexico, captive breeding without a clear restocking plan does not benefit the wild population and should therefore not be a priority. The optimal strategy for manatee recovery is to enhance the natural reproduction of wild populations. Protection of manatee habitat should ensure that there is suitable shelter, foraging and reproductive grounds, with adequate connectivity.

(2) Transfer of wild manatees to rehabilitation centres should be carried out with the final objectives of rehabilitation and restocking. We do not advocate against parks and zoos; we recognize that the expertise and facilities they offer are paramount for achieving the manatee recovery programme objectives. However, their role should be strengthened through adaptation of their management plans and protocols according to the recovery objectives and the creation of quarantine and pre-release facilities. International monitoring protocols exist to assess post-release adaptation success. These recommend using subcutaneous microchip tags and telemetry equipment for monitoring manatee survival, behaviour and acclimation to the wild and, ultimately, the reproductive contribution of released individuals to the wild population (Adimey et al., 2016). This would allow assessment of the effectiveness of rehabilitation strategies in the long-term. Manatees judged as unsuitable for return to the wild could still be used for exhibition, research and educational purposes, which would help cover the financial costs of rehabilitation programmes.

(3) Pre-release preparation and release sites could be established in the two regions that correspond to genetically identified populations. In the Gulf of Mexico, the Alvarado lagoon system, the Pantanos de Centla Biosphere Reserve and the Terminos Lagoon Protection Area offer optimal conditions. On the eastern Yucatan Peninsula, along the coast of Quintana Roo State, several natural lagoons could easily be adapted as release sites. It has been suggested that the genetic profile of the individual should be considered when selecting the release region (Luna et al., 2012), to avoid inbreeding and outbreeding depression and genetic swamping (Frankham et al., 2010). A national studbook is required for the genetic records of individuals.

(4) The manatee advisory committee should be restored, to support government authorities in the development of an integrated management strategy. Government and scientists must work together closely and establish an interactive feedback loop in which authorities inform scientists about the information required for decision-making, and scientists conduct research to provide this information. The committee could coordinate manatee release activities and post-release monitoring, as well as maintain the information repositories. Multi-stakeholder partnerships are key to the success of rehabilitation and release programmes (Adimey et al., 2016). Leadership and coordination of the Ministry of the Environment and Natural Resources are also necessary, to secure federal funding and access other financial sources to cover the cost of the recovery programme in the long term and to strengthen cooperation with neighbouring countries, particularly Belize and the USA.

These four aspects of management for the Antillean manatee are necessary and complementary. In the absence of such management, conservation efforts in Mexico will have limited effects on the recovery of the manatee at either national or regional levels. We documented this case to help avoid repetition of decision-making without thorough consideration of all consequences-positive and negative-of any proposed actions in the future of manatee conservation in Mexico.

\section{Acknowledgements}

We thank R. Sánchez-Ockruky, L. D. Olivera-Gómez and D. Jiménez for providing information on manatees in captivity, and L. C. Colmenero-Rolon, E. Barba-Macías and two anonymous reviewers, who provided constructive comments. K. MacMillan translated and revised the English text. R. Ramos produced the map.

\section{Author contributions}

AOA conceived the central idea, prepared the proposed management strategy, and carried out the institutional and management analyses. DNCM provided information on manatee management in captivity within international and national contexts, and documented the regional experiences of post-rehabilitation releases.

\section{References}

Abellera, B., Calleson, S., Deutsch, C., DeWit, M., Duncan, M., Edwards, H. et al. (2007) Florida Manatee Management Plan, (Trichechus manatus latirostris). Florida Fish and Wildlife Conservation Commission, Tallahassee, USA. Http://www. colliercountyfl.gov/home/showdocument?id=18398 [accessed 26 February 2018].

Adimey, N.M., Mignucci-Giannoni, A.A., Auil-Gomez, N.E., Da Silva, V.M.F., Alvite, C.M.C., Morales-Vela, B. et al. (2012) Manatee rescue, rehabilitation, and release efforts as a tool for species conservation. In Sirenian Conservation: Issues and Strategies in Developing Countries (eds E.M. Hines, J.E. Reynolds III, L. V. Aragones, A.A. Mignucci-Giannoni \& M. Marmontel), pp. 204-217. University Press of Florida, Gainesville, USA. 
Adimey, N.M., Ross, M., Hall, M., Reid, J.P., Barlas, M.E., Diagne, L.W.K. \& Bonde, R.K. (2016) Twenty-six years of post-release monitoring of Florida manatees (Trichechus manatus latirostris): evaluation of a cooperative rehabilitation program. Aquatic Mammals, 42, 376-391.

Ainsworth, G.B., Aslin, H.J., Weston, M.A. \& Garnett, S.T. (2016) Do social values influence levels of conservation effort in threatened species? The case of two Australian chats. Oryx, 50, 636-645.

Auil, N. (1998) Belize Manatee Recovery Plan. UNDP/GEF Coastal Zone Management Project, Belize.

Boede, E.O. \& Mujica-Jorquera, E. (2016) Rescue and handling of Antillean manatees Trichechus manatus manatus in Venezuela 1992-2014. International Zoo Yearbook, 50, 193-202.

Bonde, R., Keith, L., Ward, L., Reid, J., Pitchford, T., Deutsch, C. et al. (2003) Evaluating the post-release success of rehabilitated manatees in Florida, 1973-2002. In Abstracts of the 15th Biennial Conference on the Biology of Marine Mammals, Greensboro, USA.

Bossart, G.D. (1999) The Florida manatee: on the verge of extinction? Journal of the American Veterinary Medical Association, 214, 1178-1183.

Brook, S.M., Dudley, N., Mahood, S.P., Polet, G., Williams, A. C., Duckworth, J.W. et al. (2014) Lessons learned from the loss of a flagship: the extinction of the Javan rhinoceros Rhinoceros sondaicus annamiticus from Vietnam. Biological Conservation, 174, 21-29.

Castelblanco-Martínez, D.N., Nourisson, C., Quintana-Rizzo, E., Padilla-Saldívar, J.A. \& Schmitter-Soto, J.J. (2012) Potential effects of human pressure and habitat fragmentation on population viability of the Antillean manatee Trichechus manatus manatus: a predictive model. Endangered Species Research, 18, 129-145.

Colmenero-Rolón, L.C. \& Hoz Zavala, M.E. (1986) Distribución de los manatíes, situación y su conservación en México. Anales del Instituto de Biología, Universidad Nacional Autónoma de México, Serie Zoología, 56, 955-1020.

Corkeron, P. (2002) Captivity. In Encyclopedia of Marine Mammals (eds W.F. Perrin, B. Wursig \& J.G.M. Thewissen), pp. 192-197. Academic Press, San Diego, USA.

Frankham, R., Ballou, J.D. \& Briscoe, D.A. (2010) Introduction to Conservation Genetics, 2nd edition. Cambridge University Press, Cambridge, UK.

Hartman, D.S. (1979) Ecology and behavior of the manatee (Trichechus manatus) in Florida. Special Publication No. 5. The American Society of Mammalogists, Pittsburgh, USA.

Hunter, L.T.B., White, P., Henschel, P., Frank, L., Burton, C., Loveridge, A. et al. (2013) Walking with lions: why there is no role for captive-origin lions Panthera leo in species restoration. Oryx, 47, 19-24.

IUCN (1998) Guidelines for re-introductions. Prepared by the IUCN/SSC Re-introduction Specialist Group. IUCN, Gland, Switzerland and Cambridge, UK. Https://portals.iucn.org/library/ efiles/documents/PP-005.pdf [accessed 26 February 2018].

Lima, R.P.d., Alvite, C.M.D.C. \& Vergara-Parente, J.E. (2007) Protocolo de reintrodução de peixes-bois-marinhos no Brasil. Ibama-MA, Instituto Chico Mendes, São Luis, Brasil.

Luna, F.O., Bonde, R.K., A ttademo, F.L.N., SAunders, J.W., Meigs-Friend, G., Passavante, J.Z.O. \& Hunter, M.E. (2012) Phylogeographic implications for release of critically endangered manatee calves rescued in Northeast Brazil. Aquatic Conservation: Marine and Freshwater Ecosystems, 22, 665-672.

Marmontel, M., Odell, D.K. \& Reynolds, J.E. (1992) Reproductive biology of South American manatees. In Reproductive Biology of
South American Vertebrates (ed. W.C. Hemlett), pp. 295-312. Springer, New York, USA.

Martin, T.G., Nally, S., Burbidge, A.A., Arnall, S., Garnett, S. T., HAYWARD, M.W. et al. (2012) Acting fast helps avoid extinction. Conservation Letters, 5, 274-280.

Mercadillo-Elguero, M.I., Castelblanco-Martínez, D.N. \& PAdilla-SAldivar, J.A. (2014) Behavioral patterns of a manatee in semi-captivity: implications for its adaptation to the wild. Journal of Marine Animals and their Ecology, 7, 31-41.

Miller, E.A. (ed.) (2000) Minimum Standards for Wildlife Rehabilitation, 3rd edition. International Wildlife Rehabilitation Council \& National Wildlife Rehabilitators Association, St. Cloud, USA.

Morales-Vela, B. (2017) Daniel, the orphaned manatee, returns to the protection offered by transboundary protected areas. Sirenews, $67,16-17$

Morales Vela, B. \& Olivera Gómez, L.D. (1997) Distribución del Manatí (Trichechus manatus) en la costa norte y centro-norte del estado de Quintana Roo, México. Anales del Instituto de Biología, Serie Zoología, 68, 153-164.

Morales-Vela, B., Castelblanco-Martínez, D.N. \& Olivera-Gomez, L.D. (2012) Estandarización de protocolos para la atención de crías abandonadas, rehabilitación y necropsias de manatí. Comisión de Áreas Naturales Protegidas, El Colegio de la Frontera Sur, Mexico.

Normande, I.C., Luna, F.D.O., Malhado, A.C.M., Borges, J.C.G., Viana Junior, P.C., Attademo, F.L.N. \& Ladle, R.J. (2015) Eighteen years of Antillean manatee Trichechus manatus manatus releases in Brazil: lessons learnt. Oryx, 49, 338-344.

Nourisson, C., Morales-Vela, B., Padilla-Saldílar, J.A., Tucker, K.P., Clark, A., Olivera-Gómez, L. et al. (2011) Evidence of two genetic clusters of manatees with low genetic diversity in Mexico and implications for their conservation. Genetica, 7, 833-842.

Ortega-Ortiz, J.A., Delgado-Estrella, A. \& Ortega-Argueta, A. (2004) Marine mammals in the Gulf of Mexico: current knowledge and recommendations for their conservation. In Environmental Analysis of the Gulf of Mexico (eds K. Withers and M. Nipper; eds M. Caso, I. Pisanty and E. Ezcurra, Spanish version), pp. 63-80. Texas A\&M University, Corpus Christi, USA.

Pérez, I., Anadón, J.D., Díaz, M., Nicola, G.G., Tella, J.L. \& Giménez, A. (2012) What is wrong with current translocations? A review and a decision-making proposal. Frontiers in Ecology and the Environment, 10, 494-501.

Quintana-Rizzo, E. \& Reynolds III, J.E. (2010) Regional management plan for the West Indian manatee. CEP Technical Report no. 48. United Nations Environment Programme, Kingston, Jamaica.

SÁNChEZ OKRUCKY, R. (2009) The history of rescued manatees in Mexico: where we came from and where we are. In 2009 International Sirenian Conference, Atlanta, USA.

SEMARNAT/CONANP (2010) Programa de Acción para la Conservación de la Especie: Manatí (Trichechus manatus manatus). Compiled by L.D. Olivera Gómez, A. Ortega-Argueta, B. Morales Vela and L.C. Colmenero Rolón. México.

SNyder, N.F.R., Derrickson, S.R., Beissinger, S.R., Wiley, J.W., Smith, T.B., Toone, W.D. \& Miller, B. (1997) Limitations of captive breeding: reply to Gippoliti and Carpaneto. Conservation Biology, 11, 808-810.

Wilson, K.A., Carwardine, J. \& Possingham, H.P. (2009) Setting conservation priorities. Annals of the New York Academy of Sciences, $1162,237-264$. 


\section{Biographical sketches}

Alejandro Ortega-Argueta researches threatened species recovery and wildlife management. He is particularly interested in the social dimensions of management systems, including policy, planning, governance and evaluation. $\mathrm{He}$ is the former Secretary of the Manatee Advisory Committee in Mexico and was commissioned to prepare the Manatee Recovery Plan of Mexico. Delma Nataly CASTelblanco-Martinez is a conservation biologist studying aquatic vertebrates in Latin America. Her work focuses on conservation issues, population dynamics, behaviour and ecology of aquatic mammals, particularly manatees. She is a member of the IUCN Sirenian Specialist Group and is currently conducting a long-term megafauna monitoring project in the Caribbean. 